\title{
Simultaneous Method for Determination of Emtricitabine, Tenofovir Disoproxil Fumarate, Elvitegravir and Cobicistat in Tablets by HPLC
}

R. K. GUMMALURI*, T. V. N. PARTHASARATHI AND G. ANJANAMADHULIKA

Department of Chemistry, MVGR College of Engineering (Autonomous), Vijayaram Nagar Campus, Chintalavalasa, Vizianagaram-535 005, India

Gummaluri, et al.: Determination of Emtricitabine, Tenofovir Disoproxil Fumarate, Elvitegravir and Cobicistat by HPLC

The present study provides us a single analytical tool for the determination of elvitegravir, cobicistat, emtricitabine and tenofovir disoproxil fumarate in dosage forms. This method helps us to separate and detect the four active pharmaceutical ingredients in a single run. The objective is to develop and validate a simple reverse phase liquid chromatography method for the simultaneous determination of emtricitabine, tenofovir disoproxil fumarate, elvitegravir and cobicistat in dosage tablets. For this method, an Agilent 1200, high performance liquid chromatography system, Atlantis C18 column $(100 \times 4.6 \mathrm{~mm}, 5 \mu \mathrm{m})$ as stationary phase and a gradient mixture of $0.1 \%$ trifluoroacetic acid and acetonitrile was used as mobile phase. The gradient program was adjusted at $1.0 \mathrm{ml} / \mathrm{min}$ flow rate and $10 \mu \mathrm{l}$ injection volumes were maintained. The eluted compounds were monitored at $240 \mathrm{~nm}$. The column oven temperature was maintained at $30^{\circ}$. The developed chromatographic method was validated for selectivity, linearity, precision, accuracy, sensitivity, robustness, and system suitability.

Key words: Elvitegravir, cobicistat, emtricitbine, tenofovir disoproxil fumerate, HPLC method validation

Stribild ${ }^{\circledR}$ is a prescription medicine approved by the U.S. Food and Drug Administration (FDA), marketed by Gilead Science, used in the treatment of HIV-1 in adults who has never taken anti-human immunodeficiency virus (anti-HIV) medicines before. This tablet (daily once) serves as an alternative for consuming several pills per day by a patient. Stribild, also known as 'Quad', is a fixed-dose combination tablet containing four medications viz., elvitegravir (ELV, $150 \mathrm{mg}$ ), an HIV integrase strand transfer inhibitor (HIV1 INSTI), cobicistat (COB, $150 \mathrm{mg}$ ), a CYP3A inhibitor, also a pharmacokinetic booster to increase the effectiveness of ELV, emtricitabine (EMT, $200 \mathrm{mg}$ ), a nucleoside reverse transcriptase inhibitor (NRTI) and tenofovir disoproxil fumerate (TDF, $300 \mathrm{mg}$ ), a nucleotide reverse transcriptase inhibitor (NtRTI). The integrase inhibitor (ELV) blocks integrase enzyme while NRTIs (EMT and TDF) block reverse transcriptase enzymes of HIV. By blocking integrase and reverse transcriptase enzymes, the drugs in combination prevent HIV from multiplying and can reduce the amount of HIV in the body ${ }^{[1-5]}$. Hence, Stribild is a complete regimen for

*Address for correspondence E-mail: rk.gummaluri@gmail.com

July-August 2016 the treatment of HIV infection and is considered to be much more convenient method of taking these antiHIV drugs.

Several methods have been published for the determination of some of the drugs by thin layer chromatography (TLC) ${ }^{[6]}$, UV spectrophotometry ${ }^{[6-9]}$ and high performance liquid chromatography (HPLC) [10-18] in bulk and pharmaceutical formulations. However, a simple, robust, simultaneous HPLC-diode array detection (HPLC-DAD) method that enables the separation of four drugs in a single run is of prime importance. In view of the paucity of information, present study was conducted with an objective of development and validation of a simple reverse phase liquid chromatography (RP-HPLC) method for the

This is an open access article distributed under terms of the Creative Commons Attribution-NonCommercial-ShareAlike 3.0 License, which allows other the remix, tweak, and build up to the non-commercially, as long as the author is credited and the new creations are licensed under the identical terms.

Accepted 28 June 2016

Revised 10 Mar 2016

Received 23 Sep 2015

Indian J Pharm Sci 2016;78(4):532-537 
simultaneous determination of EMT, TDF, ELV and COB in dosage tablets.

EMT, TDF, ELV and COB samples are obtained from Mylan Laboratories Limited, Hyderabad. The structures of drugs are depicted in fig. 1. Acetonitrile and trifluroacetic acid (TFA) were obtained from Merck, Mumbai, India. All the solutions were prepared in MilliQ water (Millipore, USA). Test samples composed of Stribild ${ }^{\circledR}$ film-coated tablet containing $150 \mathrm{mg}$ of ELV, $150 \mathrm{mg}$ of COB, $200 \mathrm{mg}$ of EMT and $300 \mathrm{mg}$ of TDF are obtained from Gilead Sciences.

Chromatographic separations were carried out using Agilent-1200 series HPLC (Agilent Technologies, USA) system, consisting of binary pump, column compartment, auto sampler, and diode array detector. A chromatographic column used was Atlantis $\mathrm{C} 18$ column $(100 \times 4.6 \mathrm{~mm}, 5 \mu \mathrm{m}$, Waters Corporation, Milford, USA). Data acquisition, analysis, and reporting were performed by ChemStation chromatography software. The mobile phase was composed of $0.1 \%$ TFA in water (Pump-A) and acetonitrile (Pump-B). Mobile phase gradient program was set to achieve good separation of all four analytes of interest. The elution program was optimized as follows: At 0-2 min, linear change from A-B $(90: 10, v / v)$ to A-B $(90: 10, v / v) ; 2-3$ min, linear change from A-B $(50: 50, v / v)$ to A-B $(10: 90, v / v) ; 3-8$ min, isocratic elution A-B $(10: 90, \mathrm{v} / \mathrm{v}) ; 8-8.10 \mathrm{~min}$ linear change from $A-B(10: 90, v / v)$ to $A-B(90: 10, v / v)$ and $8.10-10 \mathrm{~min}$ isocratic elution $\mathrm{A}-\mathrm{B}(90: 10, \mathrm{v} / \mathrm{v})$. The flow rate was $1.0 \mathrm{ml} / \mathrm{min}$, injection volume was $10 \mu \mathrm{l}$ and column temperature was maintained at $30^{\circ}$.

Accurately $400 \mathrm{mg}( \pm 5 \mathrm{mg})$ of EMT, $600 \mathrm{mg}( \pm 5$ $\mathrm{mg})$ of TDF, and $300 \mathrm{mg}( \pm 5 \mathrm{mg})$ of $\mathrm{COB}$, and 300 $\mathrm{mg}( \pm 5 \mathrm{mg})$ of ELV working standards were weighed and transferred into a $100 \mathrm{ml}$ volumetric flask. The mixture is dissolved and diluted up to the mark using acetonitrile. A $5.0 \mathrm{ml}$ aliquot of the resulting solution is further diluted up to $100 \mathrm{ml}$ in another volumetric flask with acetonitrile. The prepared primary standard and working standard solutions were stored at $4^{\circ}$ and kept in dark.

Twenty tablets were weighed, and their average weight was calculated. The tablets were crushed into a homogeneous powder, and a quantity equivalent to one tablet was weighed and transferred into a 100 $\mathrm{ml}$ volumetric flask. This sample is then extracted in diluent by sonication, and filtered through Whatman 41 filter paper. The filtrate $(7.5 \mathrm{ml})$ was quantitatively transferred to a $100 \mathrm{ml}$ volumetric flask, and the solution was diluted to volume with the acetonitrile.

The developed chromatographic method was developed and validated for selectivity, linearity, precision,

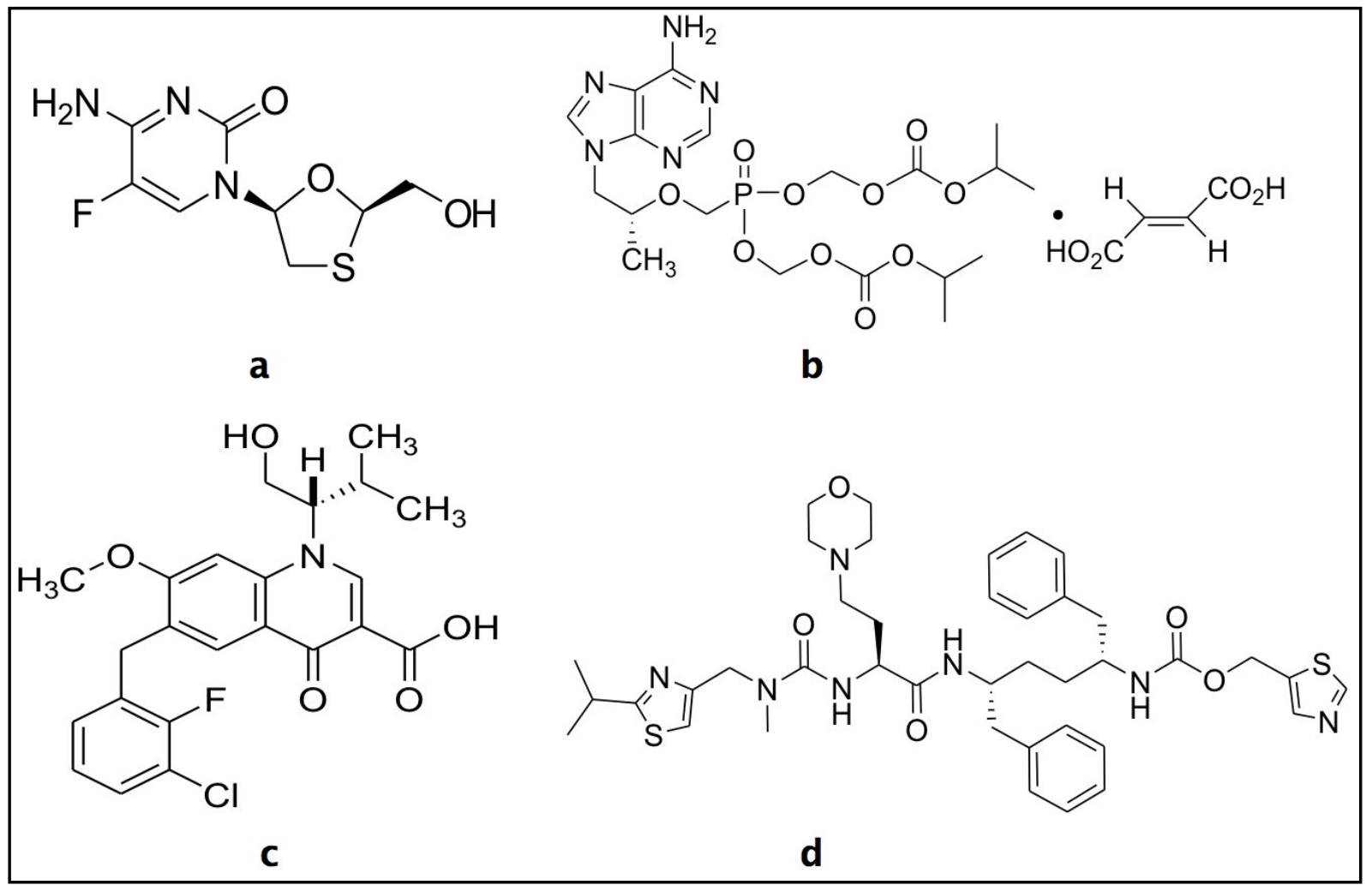

Fig. 1: Structures of analytes.

HIV drugs in Stribild tablets are (a) emtricitabine, (b) tenofovir disoproxil fumarate, (c) elvitegravir, (d) cobicistat. 
accuracy, sensitivity, robustness, and system suitability according to $\mathrm{ICH}^{[19,20]}$. The specificity of the developed liquid chromatography (HPLC-DAD) method for quantification of all the four active compounds was determined in the presence of excipients present in pharmaceutical products. In specificity study, the interference between drugs and tablet excipients were evaluated against the spectral purity obtained by carrying out the analysis for standard and sample solutions.

The system suitability was assessed by six replicate analyses of the drugs at concentrations of $200 \mu \mathrm{g} / \mathrm{ml}$ for EMT, $300 \mu \mathrm{g} / \mathrm{ml}$ for TDF, and $150 \mu \mathrm{g} / \mathrm{ml}$ each for ELV and COB. The system suitability parameters with respect to theoretical plates, tailing factor, repeatability and resolution between EMT peak and peaks of the other three analytes were defined.

Linearity of the method was evaluated at six different concentration levels by diluting the standard solutions to give solutions over the ranges $12.5-125 \%$ target concentration for all four analytes, respectively. The calibration curves were constructed at six concentrations between $25-250 \mu \mathrm{g} / \mathrm{ml}$ for EMT, 100$350 \mu \mathrm{g} / \mathrm{ml}$ for TDF and $12.5-200 \mu \mathrm{g} / \mathrm{ml}$ each of ELV and $\mathrm{COB}$.

Precision was evaluated in terms of intraday repeatability and interday reproducibility. The intraday repeatability was investigated using six separate sample solutions prepared at $100 \%$ of the target level. The interday reproducibility was studied, by preparing and analyzing triplicate sample solutions at the same concentration level of intraday repeatability.

The accuracy of the method was determined by measuring the recovery of the drugs by the method of standard additions. Known amounts of each drug corresponding to $80 \%, 100 \%$, and $120 \%$ of the target test concentrations $(0.15 \mathrm{mg} / \mathrm{ml}$ of EMT, $0.25 \mathrm{mg} / \mathrm{ml}$ of TDF, and $0.1 \mathrm{mg} / \mathrm{ml}$ each of ELV and $0.1 \mathrm{mg} / \mathrm{ml} \mathrm{COB}$ ) were added to a placebo mixture to determine whether the recipients present in the formulation led to positive or negative interferences.

Limits of detection (LOD) and quantification (LOQ) were estimated from the signal-to-noise ratio. The detection limit was determined as the lowest concentration level resulting in a peak area of 3 times the baseline noise. The quantification limit was determined as the lowest concentration level that provided a peak area with signal-to-noise ratio 10:1.
To determine the robustness of the developed method, experimental conditions were deliberately changed, and the RSD for replicate injections of EMT, TDF, ELV and COB peaks and the USP resolution factor between EMT and the other three peaks were evaluated. The mobile phase flow rate was $1.0 \mathrm{ml} / \mathrm{min}$. This was changed and studied in the sample range of $0.8-1.2 \mathrm{ml} / \mathrm{min}$ in \pm 0.2 unit intervals. The effect of stationary phase was studied by the use of LC columns from different batches at $30^{\circ}$. The chromatographic variations were evaluated for resolution between EMT and the other three analytes in system suitability with respect to retention time and percentage assay of drugs.

To assess the solution stability, standard and test solutions were kept at $25 \pm 2^{\circ}$ for $48 \mathrm{~h}$. These solutions were compared with freshly prepared standard and test solutions.

The developed method was validated, as described below, for the following parameters such as system suitability, selectivity, linearity, precision, accuracy, limit of quantification and detection. HPLC conditions were selected in order to obtain chromatograms with better resolution of adjacent peaks, especially when similar components were analyzed. In view of achieving higher peak responses and shorter analysis time of target compounds in chromatograms, the effect of different mobile phase compositions was compared. Acetonitrile-water was chosen initially and besides several mobile phase additives such as ammonium acetate, formic acid, acetic acid, TFA was found to give good chromatograms with better resolution.

Selectivity of the current method was demonstrated by good separation of the four active ingredients (EMT, TDF, ELV and COB). Further, matrix components, e.g., excipients, do not interfere with the four analytes as they have no absorbance. The relative standard deviation (RSD) values of peak area and retention time for the analytes are within $2 \%$ indicating the suitability of the system. Results of system suitability study are presented in Table 1.

Peak areas of the active ingredients and concentrations were subjected to least square linear regression analysis to calculate the calibration equations and correlation coefficients. The result shows that there is a good correlation between the peak area ratios and the concentrations of drugs in the range tested. Results of which are presented in Table 2.

Precision of this method was determined by injecting 
the standard solution of the four analytes six times. The RSD of peak area of six replicates was found to be $<2$. In all instances, the $\%$ RSD values were $<2 \%$.

Percentage recovery of the four active ingredients using this method was determined using the fixed dose combination tablet dosage forms. The results of accuracy studies from standard solution and excipient matrix are given in Table 3. Recovery values demonstrated by the above method were accurate within the desired range.

The HPLC parameters were deliberately varied from normal procedural conditions including the mobile phase flow rate $(1.0 \mathrm{ml} / \mathrm{min})$. This was varied from $0.8-1.2 \mathrm{ml} / \mathrm{min}$ with gradient \pm 0.2 units. The effect of stationary phase was studied by the use of LC columns from different batches at $30^{\circ}$. Under the studied variations, all analytes were adequately resolved, and elution orders remained unchanged. The testing solution maintained a signal-to-noise ratio over 10 in all varied conditions. The peak resolution between EMT and other three analytes were all larger than 1.5 under each variation.

The proposed method was applied to the simultaneous determination of four antiviral drugs present in fixed dosage forms which comprised of ternary mixture (Stribild film-coated tablet containing $150 \mathrm{mg}$ of ELV, $150 \mathrm{mg}$ of COB, $200 \mathrm{mg}$ of EMT, and $300 \mathrm{mg}$ of TDF). Representative chromatograms obtained from the analysis of Stribild tablets are shown in fig. 2. The differences between the amount claimed and those assayed were not found to be significant.

In this study, a validated simple and reliable RPHPLC-DAD method was described for the assay of a complex multidrug combination consisting of ELV, COB, EMT, and TDF for oral administration which is indicated as one pill, once-a-day prescription medicine used as a complete HIV-1 treatment. All the four active ingredients were successfully resolved and quantified using Atlantis $\mathrm{C} 18$ column in a relatively short run time of $8.0 \mathrm{~min}$ in gradient mode of chromatographic method. The developed method reported herein was found to be in good agreement.

\section{Acknowledgements:}

The authors were deeply indebted to and express their sincere gratitude to the principal and management for support and the permission to carry out the work in the labs of Department of Chemistry, MVGR College of Engineering (A), Vizianagaram.

TABLE 1: SYSTEM SUITABILITY PARAMETERS

\begin{tabular}{lcccc}
\hline \multicolumn{1}{c}{ Parameter } & Emtricitabine & Tenofovir & Cobicistat & Elvitegravir \\
\hline Retention time $(\mathrm{min})$ & 2.06 & 4.86 & 5.36 & 5.87 \\
Theoretical plates & 28341 & 39331 & 45708 & 39496 \\
Selectivity & - & 2.36 & 1.10 & 1.09 \\
Resolution & - & 22.16 & 4.98 & 4.63 \\
\hline
\end{tabular}

TABLE 2: LINEARITY DATA FOR FOUR DRUG ACTIVES

\begin{tabular}{lcccc}
\hline \multicolumn{1}{c}{ Parameter } & Emtricitabine & Tenofovir & Cobicistat & Elvitegravir \\
\hline Concentration range $(\mu \mathrm{g} / \mathrm{ml})$ & 2.06 & 4.86 & 5.36 & 5.87 \\
Regression equation & $\mathrm{y}=11.9486 \mathrm{x}-3.2381$ & $\mathrm{y}=11.9486 \mathrm{x}-3.2381$ & $\mathrm{y}=11.9486 \mathrm{x}-3.2381$ & $\mathrm{y}=11.9486 \mathrm{x}-3.2381$ \\
Correlation coefficient & 0.9999 & 0.9996 & 0.9999 & 0.9990 \\
LOD $(\mu \mathrm{g} / \mathrm{ml})$ & 0.01 & 0.01 & 0.1 & 0.005 \\
LOQ $(\mu \mathrm{g} / \mathrm{ml})$ & 0.03 & 0.03 & 0.3 & 0.01 \\
\hline
\end{tabular}

TABLE 3: RECOVERY DATA FOR FOUR DRUG ACTIVES

\begin{tabular}{lcccc}
\hline $\begin{array}{l}\text { \% of target } \\
\text { concentration }\end{array}$ & \% Recovery of EMT & \% Recovery of TDF & \% Recovery of COB & \% Recovery of ELV \\
\hline 80 & 101.25 & 97.65 & 101.45 & 98.74 \\
100 & 98.78 & 102.54 & 101.65 & 99.98 \\
120 & 99.12 & 98.97 & 100.47 & 100.85 \\
Average recovery & 99.72 & 99.72 & 100.19 & 99.86 \\
\hline
\end{tabular}

EMT: emtricitabine, TDF: tenofovir disoproxil fumerate, COB: cobicistat, ELV: elvitegravir 


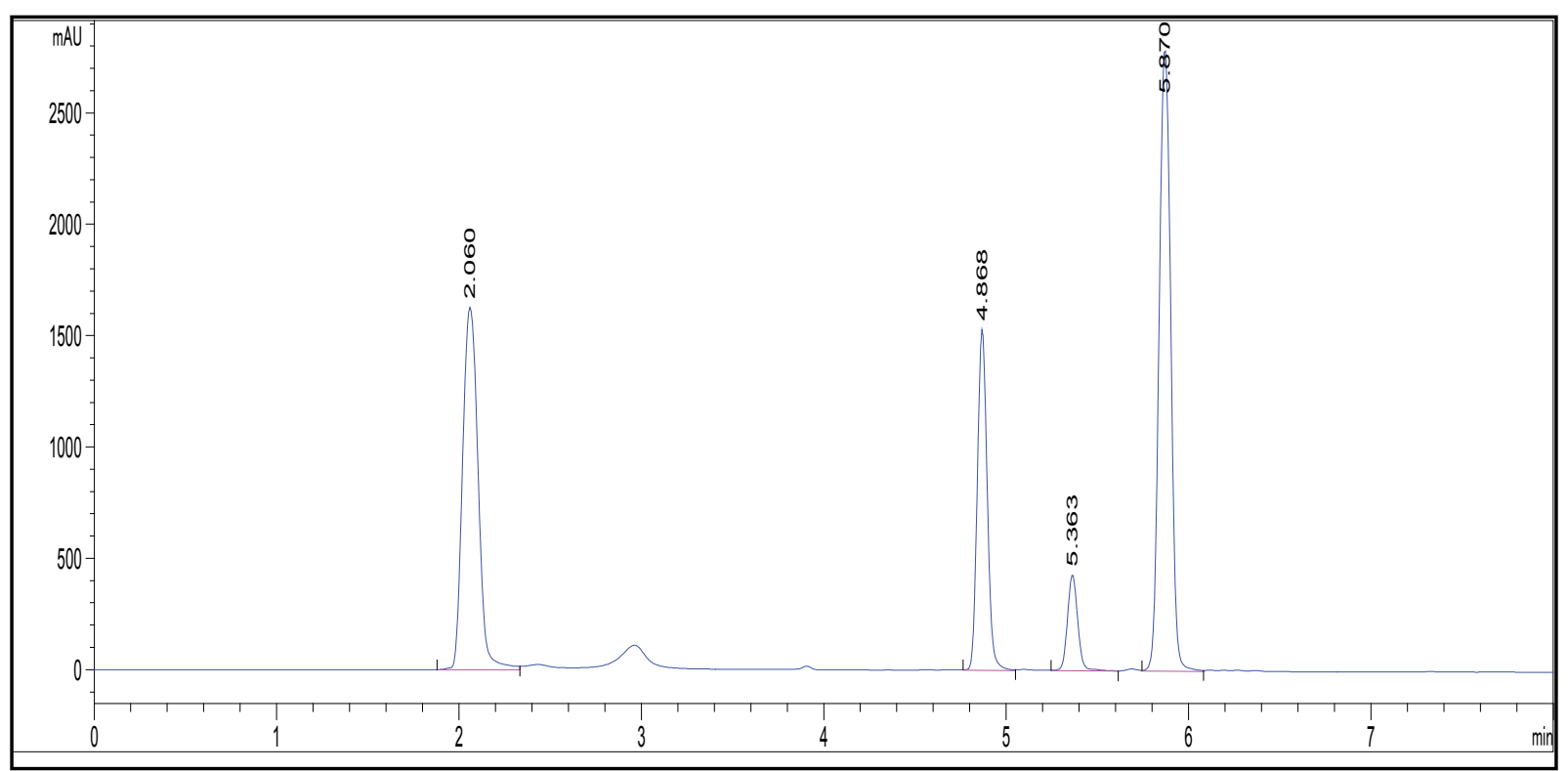

Fig. 2: A typical chromatogram of pharmaceutical fixed dosage form.

Emtricitabine (RT: $2.0 \mathrm{~min}$ ); tenofovir (RT: $4.8 \mathrm{~min}$ ); cobicistat (RT: $5.3 \mathrm{~min}$ ); elvitegravir (RT: $5.8 \mathrm{~min})$.

\section{Financial support and sponsorship:}

Nil.

\section{Conflicts of interest:}

There are no conflicts of interest.

\section{REFERENCES}

1. Olin JL, Spooner LM, Klibanov OM. Elvitegravir/cobicistat/ emtricitabine/tenofovir disoproxil fumarate single tablet for HIV-1 infection treatment. Ann Pharmacother 2012;46:1671-7.

2. Masho SW, Wang CL, Nixon DE. Review of tenofoviremtricitabine. Ther Clin Risk Manag 2007;3:1097-104.

3. Woratanarat, Kanjanabuch T, Suankratay C. Tenofovir disoproxil fumarate - associated nephrotoxicity in HIVinfected patients: a prospective controlled study. J Med Assoc Thai 2013;96:432-9.

4. Temesgen Z. Cobicistat, a pharmacoenhancer for HIV treatments. Drugs Today 2013;49:233-7.

5. Anderson PL, Kiser JJ, Gardner EM, Rower JE, Meditz A, Grant RM. Pharmacological considerations for tenofovir and emtricitabine to prevent HIV infection. J Antimicrob Chemother 2011;66:240-50.

6. Sharma MC. UV-spectrophotometric method for simultaneous estimation of tenofovir disoproxil fumarate and emtricitabine and its comparison with RP-HPLC and TLC desitometric determination. Oxidation Communications 2013;36:432-40.

7. Anindita B, Parida A, Amitkumar M, Dannanagowri S, Swapan Kumar M, Sundam Chandra S. Development and validation of spectrophotometric method for determination of emitricitabine and tenofovir disoproxil fumarate in bulk and tablet dosage form. International Journal of PharmTech Research 2011;3:1874-82.
8. Choudhari VP, Parekar SR, Chate SG, Bharande PD, Singh RR, Kuchekar BS. Development and validation of UVvisible spectrophotometric baseline manipulation method for simultaneous quantitation of tenofovir disoproxil fumarate and emtricitabine in pharmaceutical dosage form. J Spectrosc 2013;146580:6.

9. Lavanya B, Hariprasad P, Venkatapraveen A, Prasannalakshmi D. Method development and validation of combined tablet dosage form of emtricitabine and tenofovir disproxil fumerate by ultraviolet spectroscopy. Int Res J Phar 2012;3:104-108.

10. Lavanya B, Hariprasad P, Venkatapraveen A, Prasanna lakshmi D, Ramireddy M. Simultaneous estimation of emtricitabine and tenofovir disproxil fumerate by HPLC method. Der Pharmacia Lett 2012;4:99-105.

11. Fatima U, Mamatha T, Rajesh G. A novel RP-HPLC method development and validation of cobicistat in bulk drug and tablet dosage form. Der Pharmacia Sinica 2014;5:99-105.

12. Raghu Ram J, Kiran Kumar V, Appala Raju N. Development and application of liquid chromatographic method for simultaneous determination of elvitegravir, tenofovir disoproxil fumarate, emtricitabine, and cobicistat in fixed dosage form. Pharm Methods 2014;5:7-13.

13. Babu VV, Raveendra, Sharma, Pankaj K, Singhvi I. A new gradient liquid chromatographic method for simultaneous estimation of tenofovir disoproxil fumarate, cobicistat, emtricitabine and elvitegravir in bulk drug and tablet dosage form. Asian J Chem 2014;26:6233-7.

14. Ashwini S, Slunke PA, Barhate SD, Bari MM. Development and validation of simultaneous RP-HPLC method for estimation of tenofovir and lamivudine in bulk and pharmaceutical formulations. World J Pharm Res 2015;4:9951006.

15. Viswanath V, Shanmugasundaram P, Ravichandiran V. RPHPLC method for the simultaneous estimation of tenofovir disoproxil fumerate and emtricitabine in combined tablet dosage form. Int J Pharm Tech Res 2013;5:1186-95. 